\title{
Application of a Synergetic Lidar and Sunphotometer Algorithm for the Characterization of a Dust Event over Athens, Greece
}

\author{
A. Tsekeri $^{1^{*}}$, V. Amiridis ${ }^{1}$, P. Kokkalis ${ }^{2}$, S. Basart ${ }^{3}$, A. Chaikovsky ${ }^{4}$, \\ O. Dubovik ${ }^{5}$, R. E. Mamouri, ${ }^{2,6}$, A. Papayannis ${ }^{2}$ and J. M. Baldasano ${ }^{3,7}$ \\ ${ }^{1}$ Institute for Astronomy, Astrophysics, Space Applications and Remote Sensing, National \\ Observatory of Athens, Athens, Greece. \\ ${ }^{2}$ Laboratory of Lasers and Applications, National Technical University of Athens, Athens, \\ Greece. \\ ${ }^{3}$ Barcelona Supercomputing Center-Centro Nacional de Supercomputation (BSC-CNS), \\ Earth Sciences Department, Barcelona, Spain. \\ ${ }^{4}$ Institute of Physics of the National Academy of Science of Belarus, Minsk, Belarus. \\ ${ }^{5}$ Laboratoire d' Optique Atmosphérique, Universite de Lille, Lille, France. \\ ${ }^{6}$ Department of Civil Engineering and Geomatics, Cyprus Technical University, Lemesos, \\ ${ }^{7}$ Environmental Modelling Laboratory, Technical University of Catalonia, Barcelona, Spain. \\ Cyprus.
}

\section{Authors' contributions}

This work was carried out in collaboration between all authors. Author AT designed the study, performed the calculations, and wrote the first draft of the manuscript. Author VA helped in the design and had the general supervision of the study. Authors PK, REM and AP provided the lidar measurements and helped with their handling. Authors SB and JMB implemented dust model simulations. Author AC built the inversion algorithm used in the study. Author $O D$ assisted in the inversion algorithm description and the interpretation of the results. All authors read and approved the final manuscript.

Original Research Article
Received $20^{\text {th }}$ November 2013

Accepted $2^{\text {nd }}$ November 2013

Published $18^{\text {th }}$ November 2013

\section{ABSTRACT}

We present first retrievals of the Lidar-Radiometer Inversion Code (LIRIC), applied on combined lidar and sunphotometer data during a Saharan dust episode over Athens, 
Greece, on July 20, 2011. A full lidar data set in terms of backscatter signals at 355,532 and $1064 \mathrm{~nm}$, as well as depolarization at $532 \mathrm{~nm}$ was acquired from the European Aerosol Research Network (EARLINET) station of Athens and combined with Aerosol Robotic Network (AERONET) data, in order to retrieve the concentration and extinction coefficient profiles of dust. The lidar measurements showed a free tropospheric layer between $1-5 \mathrm{~km}$ above Athens, with low Angström exponent of $\sim 0.5$ and high particle depolarization ratio, $\sim 25-30 \%$, both values characteristic of dust particles. The application of LIRIC revealed high concentration profiles of non-spherical coarse particles in the layer of 0.04-0.07 ppb and a smaller fine particle component with concentrations of $\sim 0.01 \mathrm{ppb}$. The extinction coefficients at $532 \mathrm{~nm}$ ranged between 50 and $90 \mathrm{Mm}^{-1}$ for coarse nonspherical particles and between 25 and $50 \mathrm{Mm}^{-1}$ for fine particles. The retrievals were compared with modeled dust concentration and extinction coefficient profiles from the Dust Regional Atmospheric Modeling (BSC-DREAM8b) showing good agreement, especially for the coarse mode.

Keywords: Aerosol concentration; Saharan dust; LIRIC; lidar; sunphotometer; EARLINET; AERONET.

\section{INTRODUCTION}

The atmosphere of Athens, Greece, is a complex environment, incorporating local pollution and transferred air masses of marine aerosols from the Mediterranean, dust from Sahara, as well as biomass burning aerosols from fire spots in the area [1]. These mixtures are difficult to characterize, although valuable information can be deduced about their natural and anthropogenic components using appropriate retrieval methods during dust outbreaks. The current work focuses on the characterization of a dust event over Athens, using groundbased measurements with a newly developed retrieval algorithm, known as LIRIC [2,3].

Ground-based monitoring of the atmospheric column is feasible through active and passive remote sensing instruments, as the lidar system of the National Technical University of Athens (NTUA) and the sunphotometer of the National Observatory of Athens (NOA) station, part of EARLINET [4] and AERONET [5] networks, respectively. Both instruments provide valuable information about the atmospheric particles, with the sunphotometer retrieving their column-averaged microphysical and optical properties and the lidar the vertical structure of the atmosphere, providing the aerosol extinction and backscatter profiles. It has been recognized lately, that synergetic sunphotometer/lidar algorithms could combine the vertical information of the lidar measurements with the column-averaged sunphotometer data, producing more accurate retrievals. The development of these algorithms has been advancing in the frame of Aerosols, Clouds and Trace gases Research Infra Structure Network (ACTRIS -www.actris.net), utilizing the capabilities of combined AERONET/EARLINET stations in Europe.

The LIRIC algorithm has been developed within ACTRIS by the Institute of Physics, Minsk (Belarus) in collaboration with the Laboratoire d' Optique Atmospherique, Lille (France). LIRIC calculates the fine and coarse particle concentration profiles in the atmosphere, using the backscatter lidar signals at 355, 532 and $1064 \mathrm{~nm}$ and the column-averaged aerosol microphysical properties retrieved from AERONET. Moreover, if the cross-polarized measurement at $532 \mathrm{~nm}$ is provided, the algorithm has the capability of differentiating the coarse mode concentration into a spherical and a non-spherical component. 
In this study, LIRIC is applied over Athens during a Saharan dust outbreak. The retrieved concentration and extinction coefficient profiles are compared with the modeled dust concentration and extinction coefficient profiles from the BSC-DREAM8b model [6]. In Section 2 the instrumentation and methods used are described. In Section 3 the analysis results are presented and in Section 4 the conclusions.

\section{INSTRUMENTATION AND METHODS}

\subsection{Instrumentation}

The lidar data used in this study were acquired by the NTUA lidar system, part of the EARLINET network, while the sunphotometer data were acquired by the CIMEL sun-sky radiometer, part of the AERONET network. The instruments are located within $400 \mathrm{~m}$ distance, satisfying thus the requirement of co-location for the lidar and sunphotometer synergy in LIRIC.

The six-wavelength Raman lidar of NTUA performs measurements of the aerosol vertical structure in the free troposphere [7]. For nighttime measurements the elastic-backscatter signals at 355 and $532 \mathrm{~nm}$, as well as that of the $\mathrm{N}_{2}$ inelastic-backscatter signals at 387 and $607 \mathrm{~nm}$, permit the determination of the extinction and backscatter coefficients, from which the extinction-to-backscatter ratio (lidar ratio) at both wavelengths (355 and $532 \mathrm{~nm}$ ) is calculated. Quality assurance both at hardware [8] and algorithm [9] level has been assured for the NTUA lidar within the frame of EARLINET. In this study, only the daytime elastic backscatter signals are used in conjunction with coincident sunphotometric measurements, since the lidar is not capable of daytime Raman operation. Correspondingly, no information on the lidar ratio can be retrieved from the daytime lidar measurements used.

The sunphotometric measurements are provided by the NOA ground-based Atmospheric Remote Sensing Station (ARSS), which has been continuously operating since February 2009 [10]. ARSS is located on the roof of the Biomedical Research Foundation of the Academy of Athens (BRFAA) $(37.90 \mathrm{~N}, 23.80 \mathrm{E}, 130 \mathrm{~m}$ above sea level (a.s.I)). The campus is located near the city center and $10 \mathrm{~km}$ from the sea. The station is equipped with a CIMEL CE318-NEDPS9 sunphotometer for the retrieval of aerosol optical depth (AOD) at 8 wavelengths from 340 to $1640 \mathrm{~nm}$, including polarization measurements. The accuracy of the provided AOD is estimated to be of the order of \pm 0.02 regarding the level 2 (cloudscreened and quality-assured) data. The technical specifications of the instrument are given in detail in [5].

\subsection{LIRIC Algorithm}

LIRIC algorithm retrieves the fine and (spherical and non-spherical) coarse particle concentration profiles, considering that the rest of the particle properties are constant along the atmospheric column and equal to the column-averaged values provided by AERONET. The retrieval is based on a maximum-likelihood estimation of the concentration profiles, so that the lidar signals are reproduced within their measurement uncertainty and the integral of the retrieved concentrations matches the total volume concentration of the fine and coarse modes from AERONET. Furthermore, in order to avoid any unphysical values, smoothing constrains are imposed on the retrieved concentration profiles. The input and output parameters of the algorithm are shown in Table 1. 
Table 1. LIRIC algorithm input and output parameters. (Italics denote the extra input/output when the depolarization information is included in the retrieval.)

\begin{tabular}{|c|c|c|}
\hline \multicolumn{2}{|r|}{ Input } & \multirow[t]{2}{*}{ Output } \\
\hline Lidar & AERONET & \\
\hline $\begin{array}{l}\text { total elastic } \\
\text { backscatter signals at } \\
355,1064 \mathrm{~nm} \text { and } \\
\text { parallel-polarized (or } \\
\text { total) elastic } \\
\text { backscatter signal at } \\
532 \mathrm{~nm}\left(L^{*}\right) \\
\\
\text { cross-polarized elastic } \\
\text { backscatter signal at } \\
532 \mathrm{~nm}\left(L^{*}\right)\end{array}$ & $\begin{array}{l}\text { For fine and coarse particles: } \\
\text { - column-averaged extinction } \\
\text { and backscatter coefficients } \\
\left(a_{V}, b_{V}\right), \text { calculated from the } \\
\text { column-averaged } \\
\text { microphysical properties } \\
\text { (size distribution, refractive } \\
\text { index) } \\
\text { total volume concentrations } \\
(v) \\
\text { For coarse non-spherical } \\
\text { particles: } \\
\text { column-averaged extinction } \\
\text { and backscatter coefficients } \\
\left.\text { (a } a_{V}, b_{V}\right), \text { calculated from the } \\
\text { column-averaged } \\
\text { microphysical properties } \\
\text { (size distribution, refractive } \\
\text { index) of the non-spherical } \\
\text { portion of the coarse aerosol } \\
\text { load. } \\
\text { sphericity (the ratio of the } \\
\text { total volume concentration of } \\
\text { spherical and non-spherical } \\
\text { parts of coarse mode). }\end{array}$ & 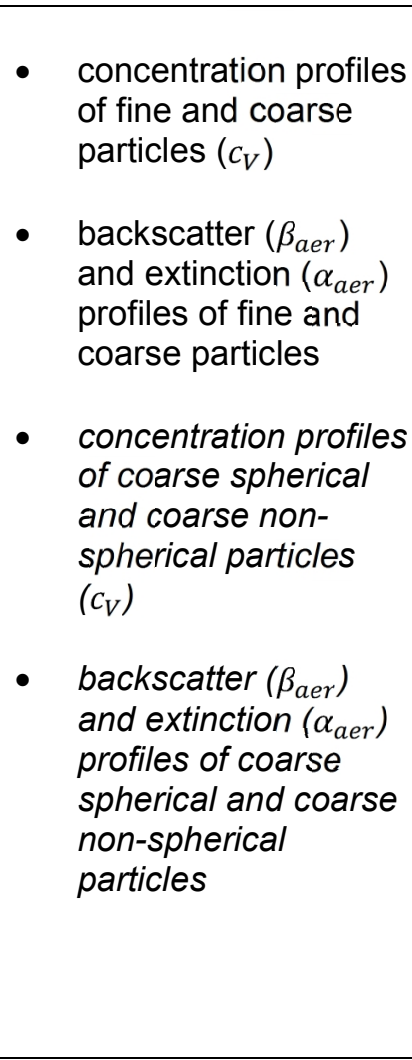 \\
\hline
\end{tabular}

In this section, a brief description of LIRIC mathematical background is given, regarding its application for total backscatter lidar signals and the retrieval of fine and coarse particle concentration profiles. For retrieving the concentration of the spherical and non-spherical parts of the coarse mode separately, the cross-polarized backscatter signal at $532 \mathrm{~nm}$ needs to be included. In this case LIRIC follows the same approach, although the equations become significantly more complicated. This description is out of the scope of this work, but it is provided in detail in $[2,3]$, and in $[11,12]$ which also include an evaluation of LIRIC on cases of dust and volcanic aerosol.

LIRIC calculates an estimation of the concentration profiles $c_{V}$ ( $V$ denotes the fine and coarse modes) that maximizes the conditional probability distribution function $P\left(c_{V} \mid L, v\right)$, for given total backscatter lidar observations $L$ and total volume concentrations $v$ from AERONET [2].

$$
P\left(c_{V} \mid L, v\right) \sim \exp \left[-\frac{1}{2}\left[\sum_{j}\left(L_{j}^{*}-L_{j}(v)\right)^{T} w_{L_{j}}^{-1}\left(L_{j}^{*}-L_{j}(v)\right)+\sum_{i} \frac{\left(v_{i}^{*}-v_{i}\left(c_{i}\right)\right)^{2}}{\sigma_{V_{i}}^{2}}+\sum_{i} \frac{E_{i}}{\sigma_{E_{i}}^{2}}\right]\right]
$$


$L_{j}^{*}$ is the vector of the measured backscattered signal and $L_{j}$ is the vector ofthe corresponding fitted signal, at $j$-th wavelength (i.e. 355,532 and $1064 \mathrm{~nm}$ ). $\mathrm{w}_{L_{j}}$ is the covariance matrix of the uncertainties in $L_{j}^{*}$, estimated based on known sources of uncertainties in lidar measurements at $j$-th wavelength. $v_{i}^{*}$ is the total volume concentration of $i$-th mode (i.e. fine and coarse) provided from AERONET, and $v_{i}$ is the corresponding estimated volume concentration, calculated as the integral of the estimated concentration over the atmospheric column, $v_{i}\left(c_{i}\right)=\int c_{i} d z . \sigma_{V_{i}}^{2}$ is the variance of the errors in $v_{i}^{*}$, estimated using AERONET retrieval uncertainties. $\frac{E_{i}}{\sigma_{E_{i}}^{2}}$ are the smoothing constrains used to avoid unphysical oscillations in the retrieved concentration profiles. $E_{i}$ is the norm of the second derivative of the $i$-th concentration profile and $\sigma_{E_{i}}^{2}$ is its variance.

Lidar measurements are averaged and corrected for range and background effects, before used as input in the retrieval algorithm in the following form:

$$
L^{*}(\lambda, z)=\frac{s^{*}(\lambda, z)}{S^{*}\left(\lambda, z_{N}\right)} \cdot R\left(\lambda, z_{N}\right) \cdot \beta_{m o l}\left(\lambda, z_{N}\right) \cdot \exp \left(2\left(\tau_{m o l}(\lambda, z)-\tau_{m o l}\left(\lambda, z_{N}\right)\right)\right)
$$

$z$ denotes the height and $\lambda$ the wavelength of the measured signals. $S^{*}$ is the time-averaged, range-corrected and normalized elastic backscatter signal, $z_{N}$ is the reference height, $R$ is the backscatter ratio $\left(R=\frac{\beta_{a e r}+\beta_{m o l}}{\beta_{m o l}}\right), \beta_{m o l}$ and $\beta_{a e r}$ are the molecular and aerosol backscatter coefficients and $\tau_{m o l}$ is the molecular optical thickness. It is assumed that at $z_{N}$ the particle scattering is negligible. $R$ is taken first equal to 1.1 for all wavelengths and then is adjusted during the retrieval process, in order to avoid any fake wavelength dependence in the lidar signal calculations. $\beta_{m o l}$ and $\tau_{m o l}$ are calculated from meteorological data, or from atmospheric standard models.

The fitted lidar signals are calculated from the estimated concentration profiles and the AERONET column-averaged extinction and backscatter coefficients.

$$
L(\lambda, z)=\left(\beta_{a e r}(\lambda, z)+\beta_{m o l}(\lambda, z)\right) \cdot \exp \left(2\left(\tau_{a e r}\left(\lambda, z_{N}\right)-\tau_{a e r}(\lambda, z)\right)\right)
$$

$L$ is the estimated backscatter signal, $\tau_{a e r}=\int \alpha_{a e r}(\lambda, z) d z$ is the aerosol optical thickness, $\beta_{a e r}, \beta_{m o l}$ and $\alpha_{a e r}$ are the aerosol and molecular backscatter coefficients and aerosol extinction coefficient, respectively. The extinction and backscatter coefficients are calculated from the AERONET column-averaged extinction and backscatter coefficients $a_{V}, b_{V}$ for fine and coarse modes $f, c$ and the estimated concentration profiles $c_{V}$ :

$$
\begin{aligned}
& \beta_{a e r}(\lambda, z)=c_{f}(z) \cdot b_{f}(\lambda)+c_{c}(z) \cdot b_{c}(\lambda) \\
& \alpha_{a e r}(\lambda, z)=c_{f}(z) \cdot a_{f}(\lambda)+c_{c}(z) \cdot a_{c}(\lambda)
\end{aligned}
$$

$a_{V}, b_{V}$ are not directly provided from AERONET. Instead, they are deducec from the refractive index and volume size distribution data, after calculating the extinction optical thickness, $\tau_{\text {ext }}$, single scattering albedo $\omega$ and phase function at $180^{\circ}, F_{11}\left(\Theta=180^{\circ}\right)$-a thorough description of AERONET retrieval algorithm is provided in $[13,14]$.

Usually, lidar measurements lack data in the first hundred meters from the ground, due to the overlap effect in the measurements [15]. To avoid any inconsistencies with the whole- 
atmospheric-column AERONET measurements, LIRIC considers a homogeneous layer up to the overlap height-, with constant concentrations $c_{V, N_{o}}$, as well as constant extinction and backscatter coefficients $a_{a e r, N_{o}}$ and $\beta_{a e r, N_{o}}$.

The best estimate of $c_{V}$ is found maximizing $P\left(c_{V} \mid L, v\right)$ in (1), or equivalently, minimizing the quadratic in its exponent (setting its gradient to zero). This is done iteratively using a

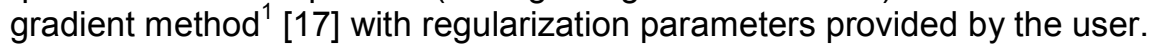

The estimated concentrations from LIRIC should not be viewed separately from the userdefined characteristics of the retrieval scheme. The definition of the regularization parameters as well as the selection of the reference height and the correction for the overlap effect can play an important role in the final result. A sensitivity analysis of LIRIC outputs with respect to the user-defined parameters of the retrieval is essential in this sense. Although this kind of analysis is beyond the scope of this work, it should be included in future efforts. In [11] this is done with varying the reference height and correcting for the overlap effect, estimating the relative errors for fine and coarse particle concentrations at $25 \%$ and $10 \%$ respectively, for the cases considered.

\subsection{BSC-DREAM8b Dust Model}

BSC-DREAM8b $[6,18,19]$ is a regional model designed to simulate and predict the atmospheric cycle of mineral dust aerosol. During model integration, calculation of the surface dust injection fluxes is made over the model grid points declared as deserts. Once injected into the air, dust aerosol is driven by the atmospheric model variables, namely the turbulent parameters in the early stage, model winds in the later phases of the process and finally, by thermodynamic processes (atmospheric water phase changes producing clouds, rain and dust wet scavenging) and land cover features which provide wet and dry deposition of dust over the Earth surface. More specifically, the main features of the model include a source function based on the arid and semi-arid categories of the $1 \mathrm{~km}$ United States Geological Survey (USGS) land use data set, a source distribution derived in [20] and dust radiative feedbacks according to [18]. Eight size bins within the $0.1-10 \mu \mathrm{m}$ radius range according to [21] are used to describe the size distribution of dust.

For the present study, the National Centers for Environmental Prediction Global Forecast System (FNL/NCEP) global meteorological files $\left(\right.$ at $1^{\circ} \times 1^{\circ}$ ) at 0 UTC are used as initial conditions and boundary conditions at intervals of $6 \mathrm{~h}$. The resolution is set to $1 / 3^{\circ}$ in the horizontal and to 24 layers extending up to approximately $15 \mathrm{~km}$ in the vertical. The domain of simulations covers northern Africa, the Mediterranean Sea, southern Europe and Middle East.

In the last years, BSC-DREAM8b model has been used for dust forecasting and dust modeling in North Africa and the Mediterranean [22]. Several case studies have outlined the good skills of the model concerning both the horizontal and vertical extent of the dust plume in the Mediterranean Basin [18,23].

\footnotetext{
${ }^{1}$ In future versions the Levenberg-Marquard method [16] will be used instead.
} 


\section{RESULTS AND DISCUSSION}

\subsection{Dust Event of July 20, 2011}

A homogeneous dust layer was advected over Athens on July 20, 2011. Its spatial evolution is shown in Fig.1, in terms of the vertically integrated dust concentration $\left(\mathrm{g} / \mathrm{m}^{2}\right)$ as simulated by BSC-DREAM8b for the period of 19 to 21 of July.

BSC-DREAM8b Dust loading $\left(\mathrm{g} / \mathrm{m}^{2}\right)$ and $3000 \mathrm{~m}$ wind
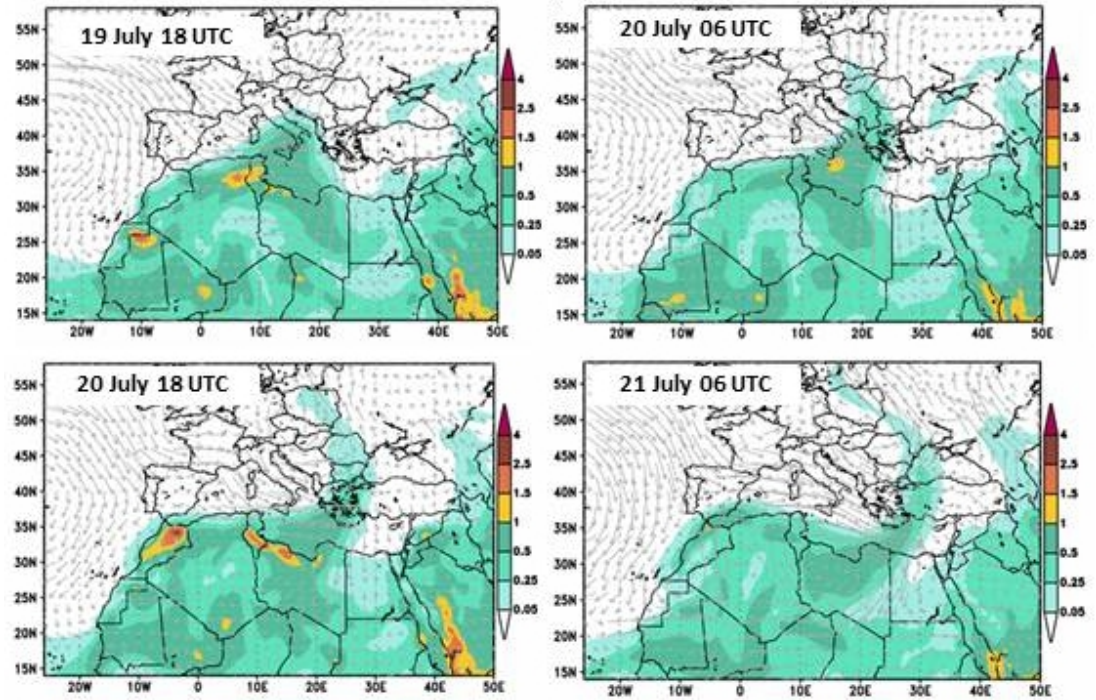

Fig. 1. Dust loading $\left(\mathrm{g} / \mathrm{m}^{2}\right)$ and $3000 \mathrm{~m}$ wind fields over Europe for the dust event on July 20, 2011, as simulated by the BSC-DREAM8b model (from 18:00 UTC July 19 to 06:00 UTC July 21).

The AOD at selected spectral channels and the Ångström exponent are derived from the direct CIMEL sunphotometer measurements over Athens. In Fig. 2, the temporal evolution of AOD and Angström exponent shows the quick arrival of the desert plume at Athens AERONET station. The AOD increases significantly (Fig. 2 -lower panel) and the Angström exponent decreases in an inverse correspondence (Fig. 2 -upper panel). Moreover, the AERONET volume size distribution of July 20 exhibits a predominant coarse mode (Fig. 3), indicating desert dust conditions.

From the other hand, on the previous day of the dust episode, July 19, the AODs are monotonously increasing with large Angström exponents, indicating the presence of a strong aerosol load consisting mainly of fine particles. Although the origin of these particles is unknown, they are most probably not dust, possible causing mixed conditions after the arrival of the dust plume. 
Angstrom exponent, AOD (AERONET)

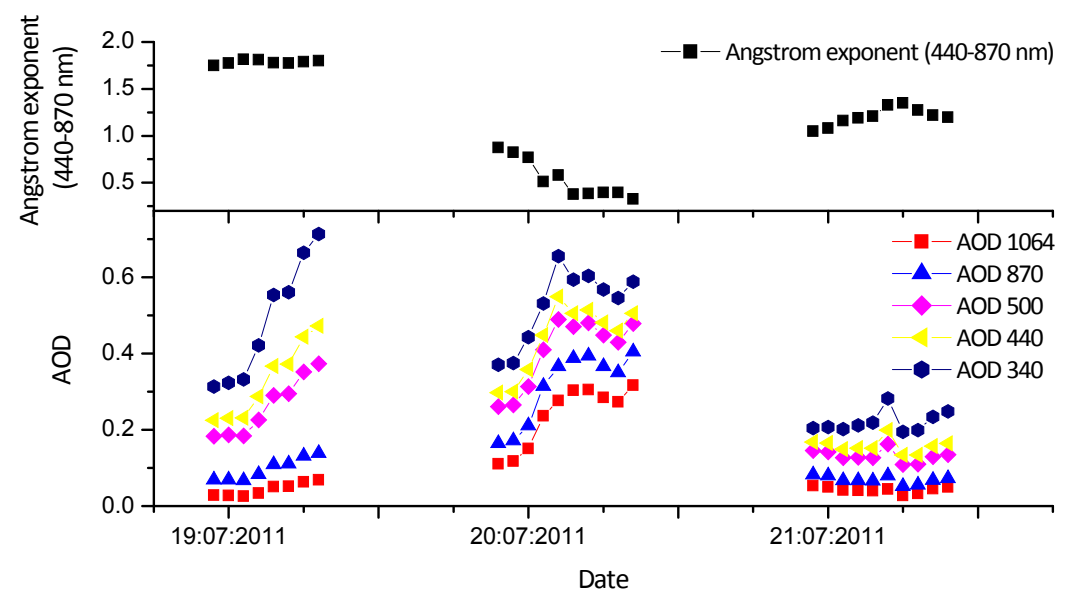

Fig. 2. Temporal evolution of the AOD at five CIMEL wavelengths $(340-1064 \mathrm{~nm})$ (lower panel) and the Angström exponent (440-870 nm) (upper panel), from 19 to 21 July, 2011, showing the arrival of the dust plume over Athens on July 20.

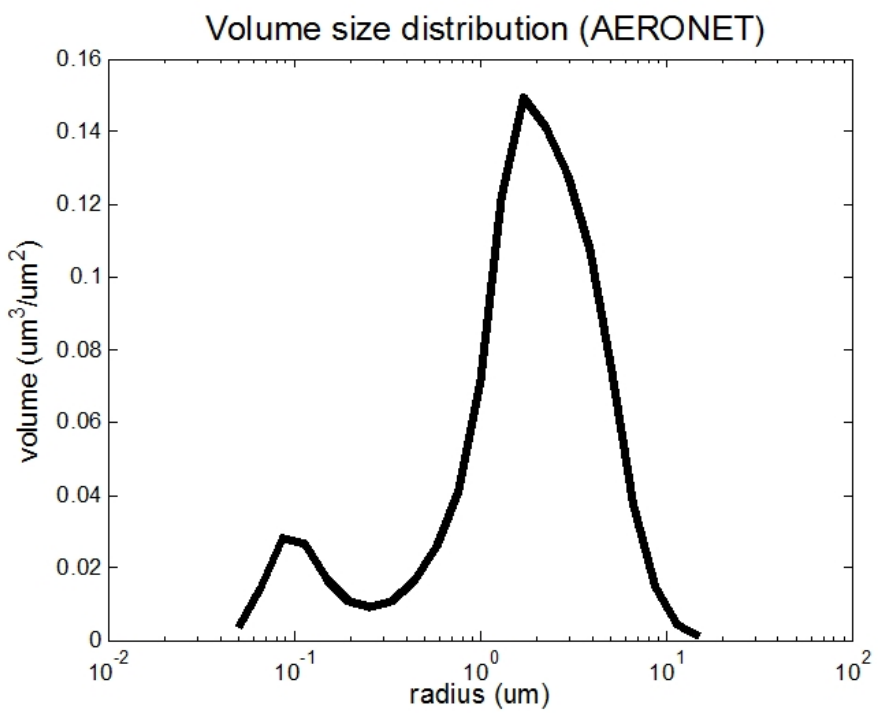

Fig. 3. Volume size distribution over Athens, from AERONET, on 13:33 UTC July 20, 2011.

According to the lidar observations, there is a distinct homogeneous aerosol vertical structure evolving during the period under study. This is shown in Fig. 4, in the time-height cross section of the lidar range corrected signals at $1064 \mathrm{~nm}$, for daytime and nighttime measurements. The lidar data used in LIRIC retrieval are from the time period within the white rectangle in Fig. 4. Backscatter coefficient profiles were calculated using the Klett method [24], assuming lidar ratios of 63, 62 and 50 at 355, 532 and $1064 \mathrm{~nm}$, respectively (Fig. 5 -left panel).These lidar ratios are deduced using the AERONET AODs, assuming a 
constant profile for the incomplete overlap region below $1.5 \mathrm{~km}$. (In general, the full overlap of the system varies between $0.7-1.5 \mathrm{~km}$ a.s.l. depending on the alignment of the laser beam and the detected wavelength [25]. In addition, these values are consistent with climatological lidar ratio values based on a statistical analysis of 10-year Raman lidar retrievals (NTUA lidar group - personal communication)). Based on the assumed lidar ratios, linear particle depolarization profiles used in LIRIC were calculated from signals calibrated with the \pm 45 degree method introduced by [26]. The particle depolarization ratio at $532 \mathrm{~nm}$ is in the range of $25-30 \%$ (Fig.5 -right panel), which is characteristic for dust particles [19].

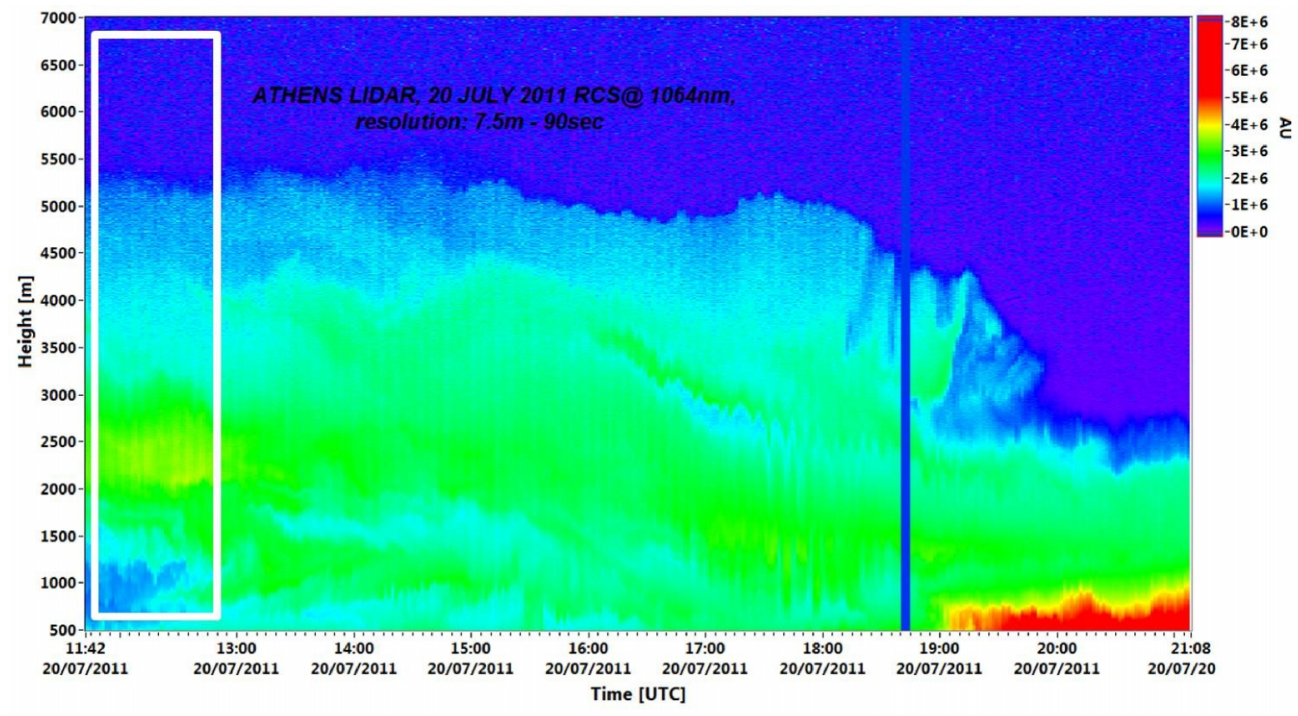

Fig. 4. Time-height cross section of the lidar range corrected signals at $532 \mathrm{~nm}$ (arbitrary units) measured on July 20, 2011, over Athens.
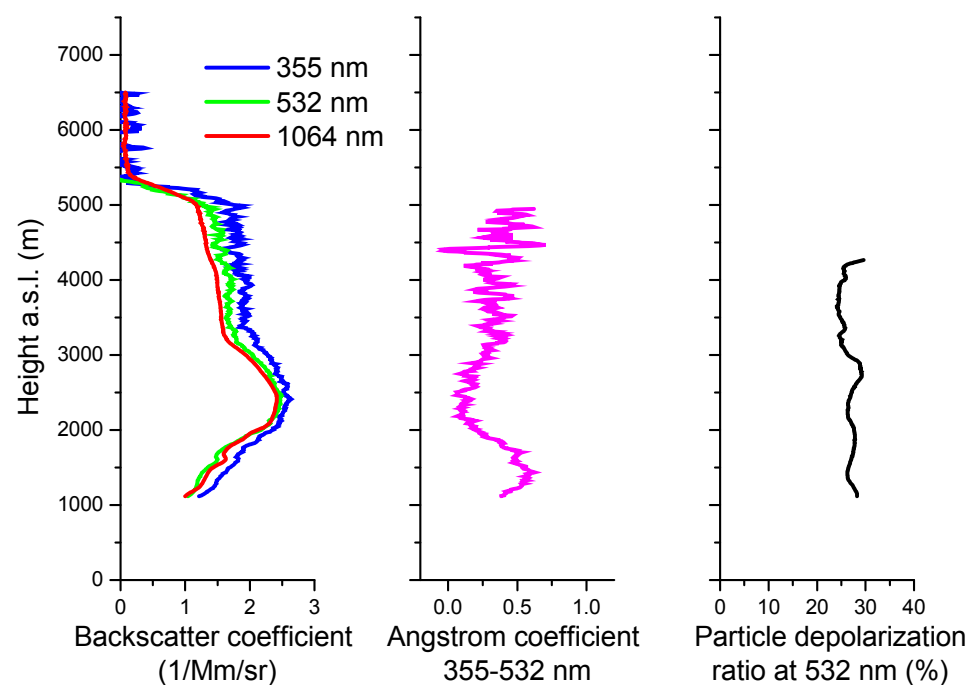

Fig. 5. Retrieved backscatter coefficients at 355, 532 and $1064 \mathrm{~nm}$ (left panel), Ångström exponent (355-532 $\mathrm{nm}$ ) (middle panel) and particle depolarization ratio at $532 \mathrm{~nm}$ (right panel), at July 20, 2011, for the time period within the white rectangle of Fig. 4 (11:42 to 12:42 UTC). 
Summarizing, given the BSC-DREAM8b simulations of the dust plume spatial distribution, together with the coarse-dominated size distribution from AERONET, the wavelengthindependent backscatter coefficients at 355, 532 and 1064 nm (low Ångström exponent) and the strong depolarization effect on the backscatter signal at $532 \mathrm{~nm}$, this layer can be attributed mostly to Saharan dust aerosols advected over Athens.

\subsection{LIRIC Results}

Using LIRIC with inputs the column-averaged microphysical properties of the particles from AERONET together with the elastic backscatter signals at 355, 532 and $1064 \mathrm{~nm}$ and the cross-polarized signal at $532 \mathrm{~nm}$ measured from the NTUA lidar, we retrieved the concentration profiles of fine, coarse spherical and coarse non-spherical particles. Fig. 6 shows the measured backscatter lidar signals and the corresponding backscatter signals calculated from LIRIC. Overall, the LIRIC signals calculated from the retrieved concentrations fit the measured lidar signals very well.

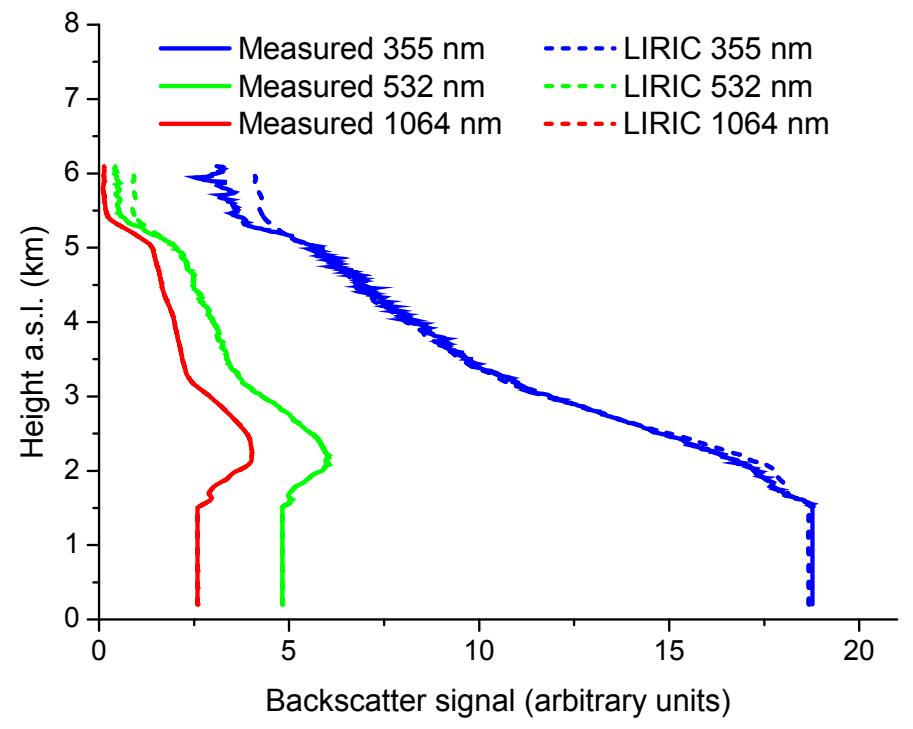

Fig. 6. Comparison of the measured backscatter lidar signals at 355, 532 and $1064 \mathrm{~nm}$ (solid lines) with the corresponding calculated backscatter signals from LIRIC (dash lines), for the dust event of July 20, 2011, over Athens.

To evaluate further LIRIC retrievals, we compare in Fig. 7 the LIRIC backscatter coefficient profile at $532 \mathrm{~nm}$, with the backscatter coefficient at $532 \mathrm{~nm}$ retrieved from the NTUA backscatter lidar measurements with the Klett method. A lidar ratio of $62 \mathrm{sr}$ is used for the Klett method, so as the retrieved extinction profile reproduces the AOD measured from AERONET. The LIRIC backscatter coefficient is calculated as the sum of the columnaveraged fine and coarse particle backscatter coefficients from AERONET data, multiplied by the corresponding retrieved fine and coarse particle concentrations, as in (5). As shown in Fig. 7, the backscatter coefficient profiles calculated with the two different methods exhibit an excellent agreement, with LIRIC values to be slightly smaller, in the order of $\sim 3 \pm 3.5 \%$ relative to the values retrieved with the Klett method. 
In order to highlight the overall improvement of the retrieval when sunphotometer information is used instead of climatological information, Fig. 7 shows the backscatter coefficient profile calculated with Klett using a climatological lidar ratio of $50 \mathrm{sr}$ [27], as well. The climatological lidar ratio of $50 \mathrm{sr}$ results to a backscatter coefficient $\sim 20 \%$ smaller than using a lidar ratio of $62 \mathrm{sr}$. This difference is substantial, proving that the sunphotometer data are necessary for delivering accurate retrievals when the lidar ratio is not known.

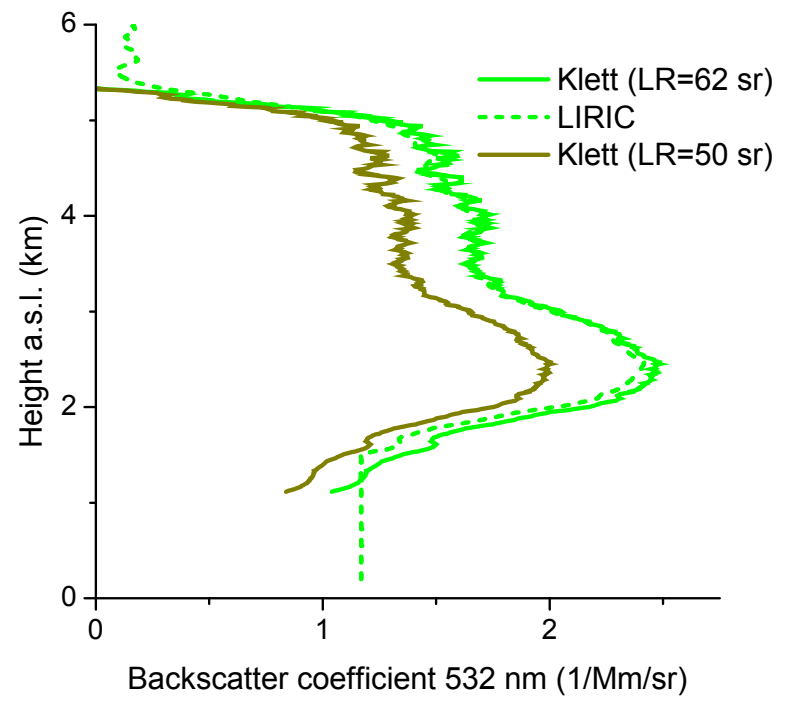

Fig. 7. Comparison of the backscatter coefficient profiles at $532 \mathrm{~nm}$ retrieved with LIRIC algorithm (dash line) and the Klett method (solid lines) for lidar ratios of $62 \mathrm{sr}$ (light green) and $50 \mathrm{sr}$ (dark green), for the dust event of July 20, 2011, over Athens.

As a final evaluation step, we compared the modeled dust concentration profile from BSCDREAM8b with the calculated concentration profiles from LIRIC (Fig. 8). The importance of the cross-polarized backscatter signal measurement at $532 \mathrm{~nm}$ for the retrieval of the nonspherical particle concentration profile (due to its high sensitivity to the non-spherical shape of dust particles [14]) is evident in Fig. 8: LIRIC utilized the polarized information to retrieve most of the coarse mode particles as non-spherical particles, resulting in a very good agreement with the coarse mode concentration of dust particles from BSC-DREAM8b.

For a direct comparison of the concentration profiles presented in Fig. 8, we transformed the LIRIC concentrations from $\mathrm{ppb}$ to $\mu \mathrm{g} / \mathrm{cm}^{3}$, using a density value of $2.35 \mathrm{~g} / \mathrm{cm}^{3}$ for the dust particles, which is the mean of the $2.1-2.6 \mathrm{~g} / \mathrm{cm}^{3}$ density range provided in literature for dust [28]. The error bars in Fig. 8 denote the range of concentrations corresponding to the dust density range. The comparison with BSC-DREAM8b shows that the coarse dust particle concentration profile is in fairly good agreement to the coarse non-spherical particle concentration profile retrieved from LIRIC. Unfortunately, the agreement for the fine particles is not as successful. However, the AERONET retrieved volume size distribution in Fig. 3, as well as the LIRIC retrieved concentrations in Fig. 8 show that the fine mode volume is quite smaller than the coarse, thus these discrepancies are not expected to be substantial.

The density value used is the same for both coarse and fine particles, assuming that the aerosol load contains only dust particles and that their density does not depend on their size. This is an approximation, since the presence of non-dust fine particles cannot be excluded 
for our case study. The large fine mode AODs present during the previous day (Fig. 2) imply that there is not only dust in the aerosol load, and that the fine mode particles probably have a different density. Unfortunately, we lack the information that would provide an alternative value for the fine mode density and this may play a role in the discrepancies between the LIRIC and the BSC-DREAM8b fine mode concentration retrievals.

Additionally, in a polluted environment as the one we consider here, the fine particles are expected to reside mainly in the planetary boundary layer (PBL), where lidar measurements lack information due to the overlap effect. Since no information is available in the first few hundred meters, LIRIC probably redistributes the fine particle concentration measured by the sunphotometer there, increasing the fine mode load at higher levels.

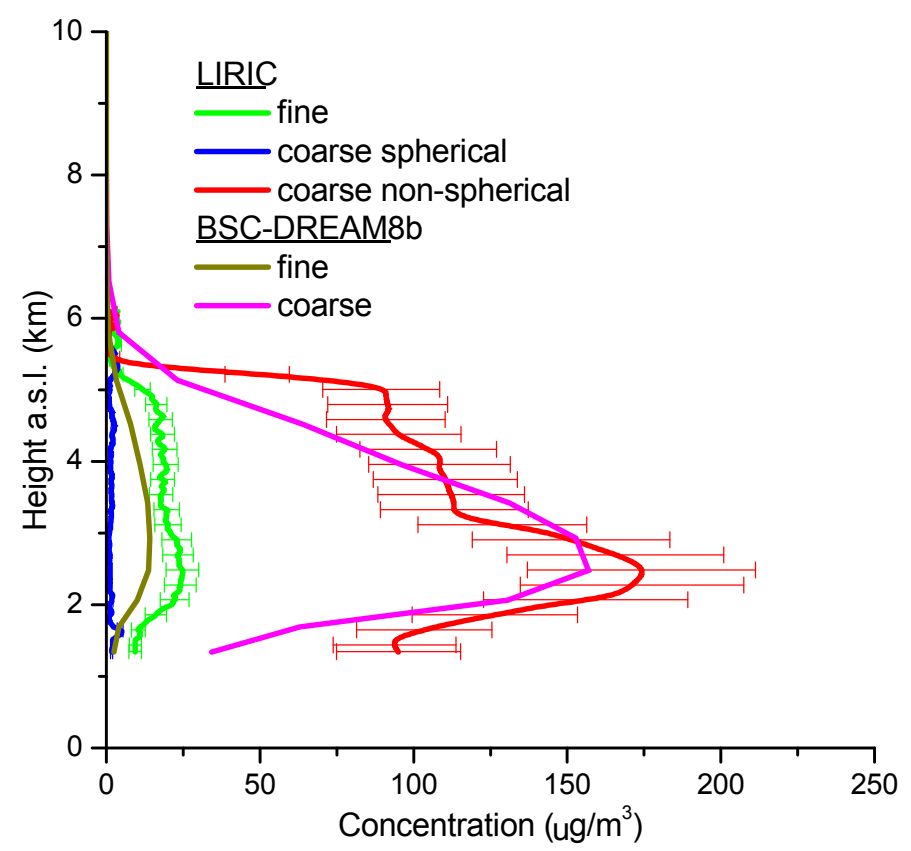

Fig. 8. Comparison of particle concentration profiles retrieved with LIRIC algorithm for fine (light green), coarse spherical (blue) and coarse non-spherical particles (red), with dust concentration profile modeled by BSC-DREAM8b for fine (dark green) and coarse dust particles (pink), for the dust event of July 20, 2011, over Athens. (The error bars denote the density range of $2.1-2.6 \mathrm{~g} / \mathrm{cm}^{3}$, used for conversions.)

Finally, the BSC-DREAM8b extinction coefficient profile at $550 \mathrm{~nm}$ is considerably lower than the extinction coefficient profile at $532 \mathrm{~nm}$ calculated from LIRIC algorithm (Fig. 9 -left panel). In order to investigate this discrepancy, we calculated the extinction coefficient profiles at $532 \mathrm{~nm}$ for fine and coarse dust particles, as the product of their BSC-DREAM8b concentrations with the fine and coarse-related column-averaged extinction, as in (6). Fig. 9 (right panel) shows a very good agreement for coarse particles, but not for fine particles. Again, the reason for this discrepancy seems to be the possible overestimation of the fine mode concentration from LIRIC, due to the reasons discussed above. 

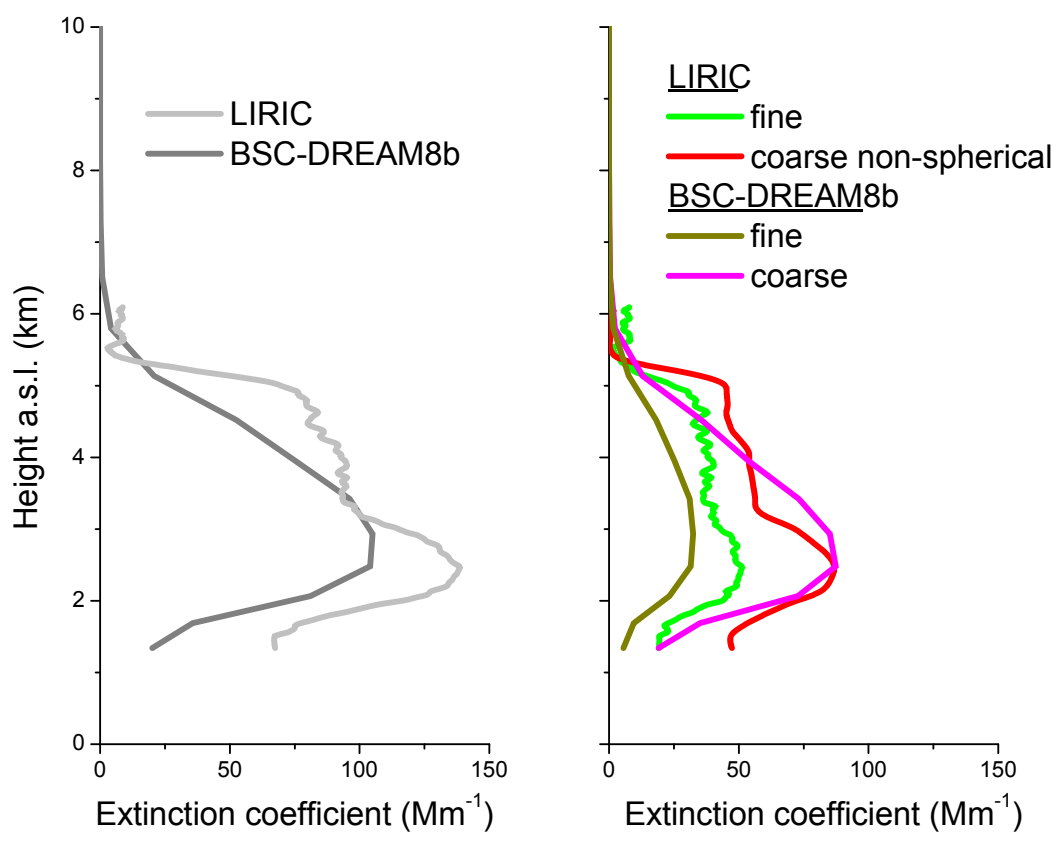

Fig. 9. Left panel: Comparison of the extinction coefficient profile at $550 \mathrm{~nm}$ from BSC-DREAM8b (dark grey), with the calculated extinction coefficient profile at $532 \mathbf{n m}$ from LIRIC algorithm (light grey). Right panel: Comparison of the extinction coefficient profiles at $532 \mathrm{~nm}$ calculated as a product of the LIRIC column-averaged fine and coarse extinction coefficients, with the corresponding concentrations of BSC-DREAM8b fine (dark green) and coarse dust particles (pink), and the LIRIC fine (light green) and coarse non-spherical particles (red), for the dust event of July 20, 2011, over Athens.

Summarizing, the comparison of the retrieved concentration and extinction coefficient profiles from LIRIC algorithm with the modeled concentration and extinction coefficient profiles from BSC-DREAM8b, call for further investigation on the following points:

1) The differences observed in the fine particle concentration profile may be due to an unavoidable artifact of LIRIC algorithm, caused by the lack of lidar information in the PBL due to the incomplete overlap region of the lidar instrument and the consequent redistribution of the PBL fine mode load measured by the sunphotometer at higher altitudes. This is why, as mentioned above, a sensitivity analysis on the various userdefined parameters of the algorithm, and in particular in this case of the overlap height, is essential for monitoring the quality of the calculated concentrations.

2) Another possible explanation, in an atmospheric environment like Athens, is the presence of fine particles from other sources that are not accounted by a dust model. It is very likely that part of the fine particle load contains remnants of the strong fine particle load present in the area on the previous day. In this case, the density value of dust used to convert the LIRIC fine particle concentration of $\mathrm{ppb}$ to $\mu \mathrm{g} / \mathrm{cm}^{3}$, should be reevaluated. 
3) The BSC-DREAM8b modeled extinction coefficient is smaller than the LIRIC extinction coefficient, due to the discrepancy in the fine mode concentration.

\section{CONCLUSION}

We presented a first evaluation of LIRIC algorithm for the concentration and extinction coefficient profile retrievals during the dust event of July 20, 2011, over Athens. The combination of lidar with sunphotometer data in LIRIC provides an advancement in aerosol characterization along the atmospheric column. Moreover, the importance of the depolarization lidar measurements in the retrieval is highlighted, due to its sensitivity to the non-spherical shape of dust particles.

We compared the results with modeled concentrations and extinction profiles from BSCDREAM8b dust model and we found that they agree fairly well for the coarse particle properties. The disagreement in the fine particle properties is mostly attributed to lack of lidar data inside the fine particles-loaded PBL, or to the presence of non-dust fine particles as remnants of a fine particle load on the previous day. Nevertheless, the comparison is quite encouraging, for both the sun photometer/lidar synergy in LIRIC, as well as the dust modeling from BSC-DREAM8b.

Sophisticated algorithms as LIRIC, but also GARRLiC algorithm (Generalized Aerosol Retrieval from Radiometer and Lidar Combined data) [29], currently developed within ACTRIS, integrate EARLINET lidar and AERONET sunphotometer observations for an improved characterization of the four-dimensional distribution of aerosols over Europe and a better understanding of climate-relevant aerosol properties. Their extensive validation is of great importance, considering the leading roles of AERONET and EARLINET on the global aerosol observation system, including the ground-based support of satellite sensors.

\section{ACKNOWLEDGEMENTS}

The research leading to these results has received funding from the European Union Seventh Framework Programme (FP7/2007-2013) under grant agreement $n^{\circ} 262254$ (ACTRIS). This publication was supported by the European Union Seventh Framework Programme (FP7-REGPOT-2012-2013-1), in the framework of the project BEYOND, under Grant Agreement No. 316210 (BEYOND - Building Capacity for a Centre of Excellence for EO-based monitoring of Natural Disasters).

We acknowledge the support and research collaboration of Ulla Wandinger and Janet Wagner from the Institute for Tropospheric Research (Germany).

\section{COMPETING INTERESTS}

Authors have declared that no competing interests exist.

\section{REFERENCES}

1. Gerasopoulos E, Amiridis V, Kazadzis S, Kokkalis P, Eleftheratos K, Andreae MO, et al. Three-year ground based measurements of aerosol optical depth over the Eastern Mediterranean: the urban environment of Athens. Atmospheric Chemistry and Physics. 2011;11:2145-2159. doi:10.5194/acp-11-2145-2011. 
2. Chaikovsky A, Bril A, Barun V, Dubovik O, Holben B, Thompson A, et al. Studying altitude profiles of atmospheric aerosol parameters by combined multi-wavelength lidar and sun sky radiance measurements. Reviewed and revised papers presented at the $22^{\text {nd }}$ International Laser Radar Conference (ILRC 2004), Matera, Italy. 2004;345348.

3. Chaikovsky A, Dubovik O, Goloub P, Tanré D, Pappalardo G, Wandinger U, et al. Algorithm and software for the retrieval of vertical aerosol properties using combined lidar/ radiometer data: Dissemination in EARLINET network. Reviewed and revised papers presented at the $26^{\text {th }}$ International Laser Radar Conference (ILRC), 2012, Porto Heli, Peloponnesus, Greece.

4. Bösenberg J, Ansmann A, Baldasano J, Balis D, Böckmann C, Calpini B, et al. EARLINET: A European Aerosol Research Lidar Network. Advances in Laser Remote sensing, Selected papers $20^{\text {th }}$ Int. Laser Radar Conference (ILRC), Vichi, France. 2000;155-158.

5. Holben BN, Eck TF, Slutsker I, Tanré D, Buis JP, Setzer A, et al. AERONET-A federated instrument network and data archive for aerosol characterization. Remote Sens. Environ.1998;66:1-16.

6. Nickovic S, Kallos G, Papadopoulos A, Kakaliagou O. Model for prediction of desert dust cycle in the atmosphere. J. Geophys. Res. 2001;106:18113-18129.

7. Mamouri RE, Papayannis A, Amiridis V, Müller D, Kokkalis P, Rapsomanikis S, et al. Multi-wavelength Raman lidar, sun photometric and aircraft measurements in combination with inversion models for the estimation of the aerosol optical and physico-chemical properties over Athens, Greece. Atmos. Meas. Tech.2012;5:17931808. doi:10.5194/amt-5-1793-2012.

8. Matthias V, Freudenthaler V, Amodeo A, Balin I, Balis D, Bösenberg J, et al. Aerosol Lidar Intercomparison in the framework of EARLINET project. 1. Instruments, Appl. Opt. 2004;43:961-976.

9. Böckmann C, Wandinger U, Ansmann A, Bösenberg J, Amiridis V, Boselli A. Aerosol lidar intercomparison in the framework of the EARLINET project. 2. Aerosol backscatter algorithms. Appl. Opt. 2004;43:977-989.

10. Amiridis V, Kafatos M, Perez C, Kazadzis S, Gerasopoulos E, Mamouri RE, et al. The potential of the synergistic use of passive and active remote sensing measurements for the validation of a regional dust model. Annales Geophysicae. 2009;27:3155-3164.

11. Wagner J. Microphysical aerosol properties retrieved from combined lidar and sunphotometer measurements. Ms. thesis. Leipzig University; 2012.

12. Wagner J, Ansmann A, Wandinger $U$, Seifert $P$, Schwarz A, Tesche M, et al. Evaluation of the Lidar/Radiometer Inversion Code (LIRIC) to determine microphysical properties of volcanic and desert dust. Atmos. Meas. Tech. Discuss. 2013;6:911948.doi:10.5194/amtd-6-911-2013.

13. Dubovik O, King M. A flexible inversion algorithm for retrieval of aerosol optical properties from Sun and sky radiance measurements. J. Geophys. Res. 2000;105(D16):20673-20696.

14. Dubovik O, Sinyuk A, Lapyonok T, Holben BN, Mishchenko M, Yang $P$, et al. Application of spheroid models to account for aerosol particle nonsphericity in remote sensing of desert dust. J. Geophys. Res. 2006;111:D11208, doi:10.1029/2005JD006619.

15. Wandinger $U$, Ansmann A. Experimental determination of the lidar overlap profile with Raman Lidar. Appl. Opt. 2002;41:511-514.

16. Levenberg K. A method for the solution of certain problems in least squares. Quart. Appl. Math. 1944;2:164-168. 
17. Press WH, Teukoisky SA, Vetterling WT, Flannery BP. Numerical Recipes: The Art of Scientific Computing, $3^{\text {rd }}$ ed. Cambridge University Press; 2007.

18. Pérez C, Nickovic S, Baldasano JM, Sicard M, Rocadenbosch F, et al. A long Saharan dust event over the western Mediterranean: Lidar, Sunphotometer observations and regional dust modeling. J. Geophys. Res. 2006;111:D15214.

19. Basart S, Pérez C, Nickovic Slobodan N, Cuevas E, Baldasano JM. Tellus B.2012;64. Accessed 19 October 2012.

Available: http://www.tellusb.net/index.php/tellusb/article/view/18539.

20. D'Almeida GA. On the variability of desert aerosol radiative characteristics. J. Geophys. Res. 1987;92:3017-3026.

21. Tegen I, Lacis AA. Modeling of particle size distribution and its influence on the radiative properties of mineral dust aerosol. J. Geophys. Res. 1996;101:19237-19244.

22. Pay MT, Jiménez-Guerrero $P$, Jorba $O$, Basart $S$, Querol $X$, et al. Spatio-temporal variability of concentrations and speciation of particulate matter across Spain in the CALIOPE modeling system. Atmos. Environ. 2012;46:376-396.

23. Amiridis V, Kafatos M, Pérez C, Kazadzis S, Gerasopoulos E,et al. The potential of the synergistic use of passive and active remote sensing measurements for the validation of a regional dust model. Ann. Geophys. 2009;27:3155-3164.

24. Klett JD. Stable analytical inversion solution for processing lidar returns. Appl. Opt. 1981;20:211-220.

25. Kokkalis P, Papayannis A, Amiridis V, Mamouri RE, Veselovskii I, Kolgotin A, et al. Optical, microphysical, mass and geometrical properties of aged volcanic particles observed over Athens, Greece, during the Eyjafjallajökull eruption in April 2010 through synergy of Raman lidar and sunphotometer measurements. Atmos. Chem. Phys. Discuss. 2013;13:9303-9320. doi:10.5194/acp-13-9303-2013.

26. Freudenthaler V, Esselborn M, Wiegner M, Heese B, Tesche M, Ansmann A, et al. Depolarization ratio profiling at several wavelengths in pure Saharan dust during SAMUM 2006. Tellus. 2009;61B:165-179.

27. Papayannis A, Amiridis V, Mona L, Tsaknakis G, Balis D, Bösenberg J, et al. Systematic lidar observations of Saharan dust over Europe in the frame of EARLINET (2000-2002). Journal of Geophysical Research. 2008;113:D10204, doi:10.1029/2007JD009028.

28. Reid JS, Jonsson HH, Maring HB, Smirnov A, Savoie DL, Cliff SS, et al. Comparison of size and morphological measurements of coarse mode dust particles from Africa. J. Geophys. Res.-Atmos. 2003;108:8593-8620.

29. Lopatin A, Dubovik O, Chaikovsky A, Goloub PH, Lapyonok T, Tanré D, et al. Enhancement of aerosol characterization using synergy of lidar and sun-photometer coincident observations: the GARRLiC algorithm. Atmos. Meas. Tech.2013;6:20652088.doi:10.5194/amt-6-2065-2013.

(c) 2013 Tsekeri et al.; This is an Open Access article distributed under the terms of the Creative Commons Attribution License (http://creativecommons.org/licenses/by/3.0), which permits unrestricted use, distribution, and reproduction in any medium, provided the original work is properly cited.

Peer-review history:

The peer review history for this paper can be accessed here: http://www.sciencedomain.org/review-history.php?iid=323\&id=10\&aid=2529 